\title{
SOLID PHASE EXTRACTION AND LC-MS/MS METHOD FOR QUANTIFICATION OF VENLAFAXINE AND ITS ACTIVE METABOLITE O-DESMETHYL VENLAFAXINE IN RAT PLASMA
}

\author{
SARFARAZ AHMAD ${ }^{l}$, MASOOM R. SIDDIQUI', MD. S. ALI' ${ }^{1 \dagger}$, SAIKH M. WABAIDUR ${ }^{2}$, MD. S. ALAM ${ }^{l}$, \\ NAWAZISH ALAM ${ }^{1}$, ZEID A ALOTHMAN ${ }^{2}$ MOONIS ALI KHAN ${ }^{2}$, MOHAMMAD R. KHAN ${ }^{2}$
}

${ }^{I}$ Department of pharmacy, Jazan university, Jazan, Saudi Arabia

${ }_{2}^{2}$ Advanced Materials Research Chair, Department of chemistry, College of Science, King Saud University, Riyadh. Saudi Arabia. 11451

\begin{abstract}
A rapid, simple, sensitive LC-MS/MS method involving a least pretreatment process has been proposed for the quantitative assessment of venlafaxine (VEN) and O-desmethyl venlafaxine (ODV) using cetirizine as an internal standard. The method was validated over the range of $1.03 \mathrm{ng} / \mathrm{mL}$ to $453.50 \mathrm{ng} / \mathrm{mL}$ (venlafaxine) and $1.32 \mathrm{ng} / \mathrm{mL}$ to $585.21 \mathrm{ng} / \mathrm{mL}$ (O-desmethyl venlafaxine). The lowest limit of quantification for venlafaxine and O-desmethyl venlafaxine was found to be $1.03 \mathrm{ng} / \mathrm{mL}$ and $1.32 \mathrm{ng} / \mathrm{mL}$, respectively. The solid phase extraction procedure provided reliable and reproducible recoveries of the drug as well as its active metabolite with no interference at their retention time. The recovery for all analyzed drugs was found to be in the range of $72.55 \%$ to $74.75 \%$. The result indicates that the developed procedure could be considered suitable for carry out simultaneous preclinical pharmacokinetics studies for VEN and ODV.
\end{abstract}

Keywords: venlafaxine, o-desmethyl venlafaxine, pharmacokinetics, solid phase extraction, LC-MS/MS

\section{INTRODUCTION}

Venlafaxine (VEN) chemically known as 1-[2-(dimethylamino)-1-(4methoxyphenyl)ethyl]cyclohexan-1-ol, is a bicyclic phenethylamine drug which is generally employed in the treatment of depression. The structure of the target drug, its major metabolites and the internal standard used in the determination process is mentioned in Figure 1, while their physical properties are mentioned in Table 1. It is one of the recent drugs used as antidepressant with peculiarity that its structure is not resemble to those of any currently used anti-depressant rather similar to an analgesic tramadol [1].<smiles>Cc1ccc(C(CN(C)C)C2(O)CCCCC2)cc1</smiles>

VEN<smiles>O=C(O)COCCN1CCN(C(c2ccccc2)c2ccc(Cl)cc2)CC1</smiles>

CET

Fig 1. The chemical structure of the target drug (VEN), its major metabolites (ODV) and the internal standard (CET)

Table 1 Physicochemical properties of VEN and ODV.

\begin{tabular}{|c|c|c|c|}
\hline Drug & Nature & Colour & Solubility \\
\hline VEN & Crystalline & White & $\begin{array}{c}\text { Very soluble in water, } \\
\text { free waters }\end{array}$ \\
\hline ODV & Crystalline & $\begin{array}{c}\text { White to off } \\
\text { white }\end{array}$ & $\begin{array}{c}\text { Soluble in Bromine } \\
\text { solution }\end{array}$ \\
\hline
\end{tabular}

VEN falls in category of compound named serotonin and norepinephrine reuptake inhibitors (SNRIs) $[2,3]$. VEN acts in such a way that it checks the reabsorption of the noradrenaline and serotonin into the brain's nerve cell. This mechanism supports in prolonging the mood lifting influence of any released noradrenaline and serotonin. In this means, the analyzed drug benefits to relieve depression. This drug can also be beneficial in relieving the depression which is accompanied by anxiety. The oral bioavailability reported for VEN is around $92 \%$. The target drug undergoes metabolism in liver and it is believed to be the major constituent excreted after a single dose of VEN is ODV and ODV-glucuronide [4]. VEN in addition to its application in the treatment of depression it was also found to have reduced the severity of "hot flashes" in menopausal ladies [5], prostate cancer in men [6], diabetic neuropathy [7].

$$
\text { O-desmethyl venlafaxine chemically called }
$$
as 4-[2-dimethylamino-1-(1-hydroxycyclohexyl) ethyl]phenol (ODV), is having similar activity to that of VEN [8]. ODV is normally a synthetic form of the main active metabolite of VEN, thus it is important to have the pharmacokinetic parameters investigated in order to observe the plasma concentration of both VEN and its metabolite ODV.

Several researchers have worked on the analytical development of the target drug using different techniques including capillary electrophoresis [9-12], capillary chromatography [13], and LC-MS/MS [14-20]. Although, few reported methods are available for quantitative analysis of VEN and ODV. The current method offers rapidity, simplicity, higher sensitivity and involving a least pretreatment process for estimation of VEN and ODV using cetirizine (CET) as an internal standard. CET was considered as internal standard because it can detected alongside the main compound under the similar experimental conditions and eluted close to the retention time of the venlafaxine hydrochloride and stable at the proposed experimental conditions as well. There was no interference noticed from the processed blank plasma at the retention time of the CET. Moreover, it is easily available and low cost compound. In addition to less sample analysis time, solid phase extraction (SPE) procedure was employed which added additional advantage to the developed LC-MS/MS method. The developed and validated bio-analytical method was successfully applied for the simultaneous estimations of venlafaxin hydrochloride and ODV.

\section{EXPERIMENTAL}

Chemicals and reagent

VEN, ODV were obtained from jubilant life sciences Ltd (NOIDA, UP India) as gift sample, while the internal standard sample cetrizine (CET) was procured from Sigma-Aldrich (St. Louis, USA). All the samples were of analytical grade. Methanol, ammonium acetate and ortho-phosphoric acid of HPLC grade were obtained from Spectrochem Pvt Ltd (Mumbai, India). Ultrapure water was obtained from Milli-Q water purification system (Millpore, MilliQ Water System, USA).

Apparatus

LC-Shimadzu LC10 from Shimadzu (Kyoto, Japan) comprising of valve for flow control, vacuum degasser, Agilent pump (Santa Clara, California) auto sampler. Mobile phase (Acetonitrile : Buffer Solution $=90: 10, \mathrm{v} / \mathrm{v}$ ) was 
pumped at a constant flow rate of $0.60 \mathrm{ml} / \mathrm{min}$. ultrasonic bath was used to degas the mobile phase before its use. The chromatographic separation was carried out using hypurity Advance $50 \times 4.6 \mathrm{~mm}, 5-\mu \mathrm{m}$ particle size analytical column (Thermo Fisher Scientific, Massachusetts, USA). On the other hand, mass spectrometric measurements were carried out using a Q-Trap API 3000 mass spectrometer (Applied Biosystem /MDS Sciex, Toronto, Canada) equipped with a Turbo Ion Spray and was operated in positive ion mode. Analyst Software version 1.4.1 (Applied Biosystems) used for controlling the equipment, data acquisition and analysis, while Microsoft Excel was used for data processing.

Standard and working solution

Standard stock solutions of $1 \mathrm{mg} / \mathrm{mL}$ in methanol of VEN and ODV and Internal standard (IS) cetrizine were prepared by weighing accurately 5 $\mathrm{mg}$ of each analyte and dissolved in $5 \mathrm{ml}$ methanol in similar volume flask. The working stock of IS (1500 ng $/ \mathrm{mL})$ was prepared in diluent solution i.e. methanol and water $(50: 50 \mathrm{v} / \mathrm{v})$, from the standard stock solution of cetirizine (IS). The analytical working standard for VEN and ODV was prepared in the range of $1.03 \mathrm{ng} / \mathrm{mL}$ to $453.50 \mathrm{ng} / \mathrm{mL}$ and $1.32 \mathrm{ng} / \mathrm{mL}$ to $585.21 \mathrm{ng} / \mathrm{mL}$, respectively by serial dilution. All the stock and working standard solution was prepared prior to start the validation and stored at $4{ }^{\circ} \mathrm{C}$.

Calibration Standard and Quality control Sample

The calibration samples were prepared at a series of concentration points of $10000.00,9000.00,4500.00,2250.00,562.50,90.00,45.00$, and 20.34 $\mathrm{ng} / \mathrm{ml}$ for VEN, and 13000.00*, 11700.00*, 5850.00*, 2925.00*, 731.25*, $117.00^{*}, 58.50^{*}$ and $26.44^{*} \mathrm{ng} / \mathrm{ml}$ for ODV*. From these two series of prepared aqueous solutions, $2.5 \%$ of each solution containing VEN and ODV was separately spiked in rat plasma. Cetirizine $25 \mu \mathrm{l}$ of $(1500 \mathrm{ng} / \mathrm{mL})$ was added to the plasma sample prior to extraction. Five replicated each of high, medium and low extracted quality control samples were prepared on each day and were used to measure the precision and accuracy of the assay procedure. Both the calibration standard and the QC samples were prepared fresh before performing the validation.

Sample preparation

Solid phase extraction (SPE) is considered as an accurate tool for the recovery of the drugs and its metabolite from plasma, several methods have been reported highlighting the application of SPE in drug extraction from plasma [21-22]. In our extraction process involving solid phase extraction (SPE) technique the spiked standards and quality control samples were vortex on Vibramax for $5 \mathrm{~min}$ and $25 \mu \mathrm{L}$ of cetirizine IS approximately (1500.00 ng/ $\mathrm{mL}$ ) was taken into polypropylene tubes and aliquot $400 \mu \mathrm{L}$ of plasma (that was stored at $-75^{\circ} \mathrm{C}$ to $-85^{\circ} \mathrm{C}$ and thawed prior to use) was added to it. After that, $50 \mu \mathrm{L}$ of $50 \%$ ortho-phosphoric acid solution was introduced into the tube and was vortex well for $5 \mathrm{~min}$ to break the drug protein binding for obtaining the improved peak resolution. The HLB cartridge $(30 \mathrm{mg} / 1 \mathrm{cc})$ was conditioned with $1.0 \mathrm{~mL}$ methanol, $1.0 \mathrm{~mL}$ of milli-Q water and then the sample was loaded to it. The plasma samples were eluted at a slow pace by maintaining vacuum pressure $(12.7 \mathrm{mmHg})$, further the cartridges was washed twice with $1.0 \mathrm{ml}$ washing solution (5\% Ammonia in HPLC grade/Milli-Q water) then the sample in the cartridge was eluted twice with $1.0 \mathrm{ml}$ methanol into the pre labeled test tube. The eluate was evaporated and dried using nitrogen evaporator (NE) and the sample was reconstituted in $500 \mu \mathrm{L}$ of the mobile phase (Acetonitrile: Buffer Solution; 90:10, v/v). The reconstituted solution was used for LC-MS/MS determination of the target drug and its metabolite. All the experiments were performed under light protected conditions.

\section{RESULTS AND DISCUSSION}

Chromatographic Conditions optimization

LC-Shimadzu LC10 from Shimadzu consisting of valve for flow control, vacuum degasser, pump auto sampler functioned to deliver mobile phase mobile phase (Acetonitrile : Buffer Solution; 90:10, v/v) at a continuous rate of $0.600 \mathrm{ml} / \mathrm{min}$. The chromatographic separation was carried out in Hypurity Advance $(50 \times 4.5) \mathrm{mm} 5 \mu$ column. Both the chromatographic and the MS/MS conditions of the current method are listed in table 2.
Table 2. Optimized LC-MS/MS chromatographic conditions for proposed method.

\begin{tabular}{|l|l|}
\hline Parameters & Values/types \\
\hline Column type & Hypurity Advance $(50 \times 4.5) \mathrm{mm}, 5 \mu \mathrm{m}$ \\
\hline Mobile Phase & $\begin{array}{l}\text { Acetonitrile: } 2 \mathrm{mM} \text { Ammonium Acetate } \\
\text { Buffer: } 90: 10, \mathrm{v} / \mathrm{v}\end{array}$ \\
\hline Column Oven temperature & $35 \pm 2{ }^{\circ} \mathrm{C}$ \\
\hline Injection Volume & $10 \mu \mathrm{L}$ \\
\hline Flow Rate & $0.600 \mathrm{~mL} / \mathrm{min}$ \\
\hline NEB & $10.0 \mathrm{psi}$ \\
\hline CUR & $9.0 \mathrm{psi}$ \\
\hline Ion Source & Turbo Ion Spray (Positive Ion Mode) \\
\hline $\mathrm{m} / \mathrm{z}$ ion, drug X & $278.20 / 121.10$ amu \\
\hline m/z ion, drug Y & $264.20 / 106.90$ amu \\
\hline m/z ion, Cetirizine(IS) & $389.0 / 201.0$ amu \\
\hline Run Time & 2.0 minutes(approx) \\
\hline RT & $\begin{array}{l}\text { Drug X 0.96 min (approx), Drug Y } 0.96 \\
\text { min (approx),Ctirizine (IS) } 1.32 \text { min } \\
\text { (approx) }\end{array}$ \\
\hline
\end{tabular}

Mass Spectrometric Conditions Optimization

A Q-Trap API 3000) LC-MS/MS (Applied Biosystem /MDS Sciex, Toronto, Canada) mass spectrometer was made to work in positive ion mode. Optimization of MS parameter was achieved using $1 \mu \mathrm{g} / \mathrm{ml}$ the target compounds. The declustering potential (DP) was optimized while ion spray voltage, nebulizing gas (zero air-15 psi) and curtain gas (nitrogen gas-20 psi) condition were kept in default mode. MS scan was carried out in positive ionization mode while the dwell time and mass width were fixed at $0.2 \mathrm{sec}$ and $\pm 10 \mathrm{amu}$, respectively. The product ion spectra were generated to ascertain the prominent product ion of the target analytes considering nitrogen as the collision gas. The established MRM conditions are summarized in Table 3.

DP- Declustering Potential; EP- Entrance Potential; CXP- Collision Cell Exit Potential; CAD- Collision Activated Dissociation; NEB- Nebulizing gas;CUR- Curtain gas; v- volt

Individual mass spectrums for parent ion of VEN (Figure 2A), ODV (Figure 2B) and IS cetirizine (Figure 2C) in methanol and Buffer Solution (2 $\mathrm{mM}$ Ammonium Formate Solution) :: 80:20, $\mathrm{v} / \mathrm{v}$ were recorded in positive ion mode. The product ion was documented for VEN in the range from $100-310$ amu (Figure 3A), while the product ion was recorded in a scan range from 95 to $290 \mathrm{amu}$ for ODV (Figure 3B) and 170 to $320 \mathrm{amu}$ for cetirizine (Figure 3C).

\section{Method Validation}

The method validation was performed considering the parameters such as specificity, selectivity, linearity, lower limit of detection (LLOD), lower limit of quantification (LLOQ), recovery, accuracy, precision and stability, the accuracy and precision determined in five replicated at low, medium, and high concentration level.

Specificity and selectivity

A number of factors such as analyte metabolite, degradation product, chemical entities in biological fluid, impurities in reagents and dust in laboratory and glassware used in the analysis causes interference in biological samples. To check the specificity of the method in plasma samples, a minimum of six different batches needs to be screened. Solution of VEN and ODV and internal standard (IS) cetrizine was prepared and injected into the LC system to check the retention time (RT) and mass transition (in case of LC-MS/MS) of all the target peak using proposed chromatographic conditions. The peaks of the three compounds are mentioned in figure $4(\mathrm{~A}, \mathrm{~B}, \mathrm{C})$. 

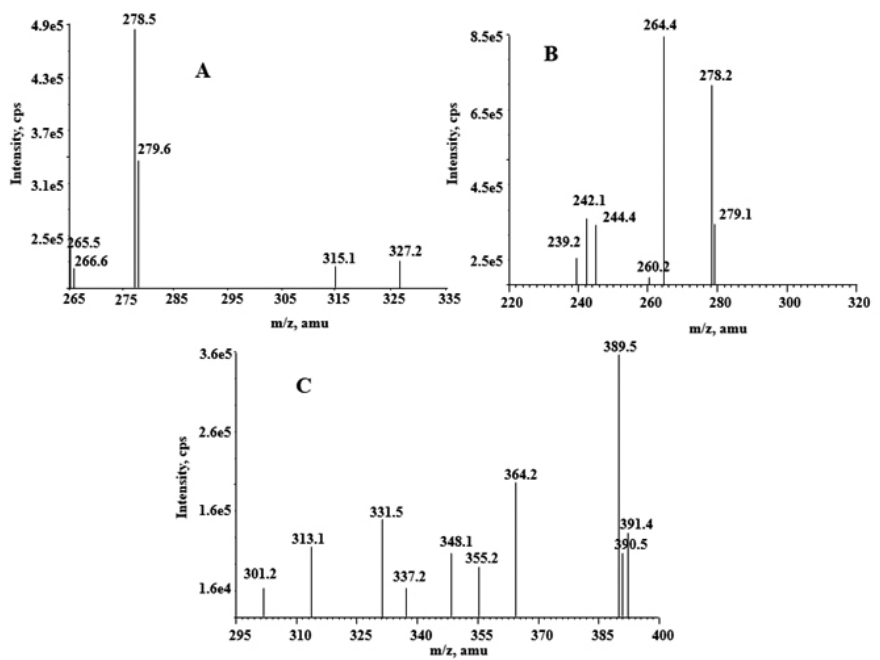

Figure 2: Mass Spectrum Q1 scan (A) VEN (B) ODV (C) IS Cetrizine
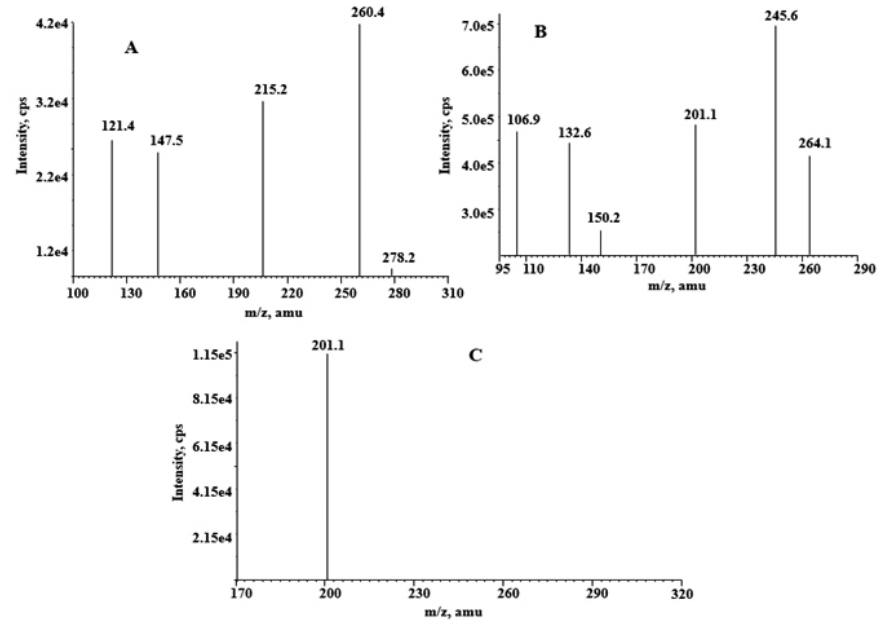

Figure 3: Mass Spectrum MS2 scan (A) VEN (B) ODV (C) IS Cetrizine.

Table 3: Optimized MRM conditions for VEN, ODV and IS.

\begin{tabular}{|c|c|c|c|c|c|c|c|c|}
\hline Analyte & Parent Ion/Product Ion & $\begin{array}{c}\text { DP } \\
(\mathrm{v})\end{array}$ & $\begin{array}{c}\text { EP } \\
(\mathrm{v})\end{array}$ & $\begin{array}{c}\text { CXP } \\
(\mathrm{v})\end{array}$ & $\begin{array}{c}\text { CAD } \\
(\mathrm{psi})\end{array}$ & $\begin{array}{c}\text { NEB } \\
(\mathrm{psi})\end{array}$ & $\begin{array}{c}\text { CUR } \\
(\mathrm{psi})\end{array}$ & $\begin{array}{c}\text { Turbo Spray Voltage (IS) } \\
(\mathrm{pv})\end{array}$ \\
\hline VEN & $278.20 / 121.10 \mathrm{amu}$ & 39 & 135 & 7.19 & 5 & 10 & 9 & -5000 \\
\hline ODV & $264.20 / 106.90 \mathrm{amu}$ & 52 & 135 & 6.0 & 5 & 10 & 9 & -5000 \\
\hline IS & $389.0 / 201.00 \mathrm{amu}$ & 27 & 135 & 12.0 & 5 & 10 & 9 & -5000 \\
\hline
\end{tabular}
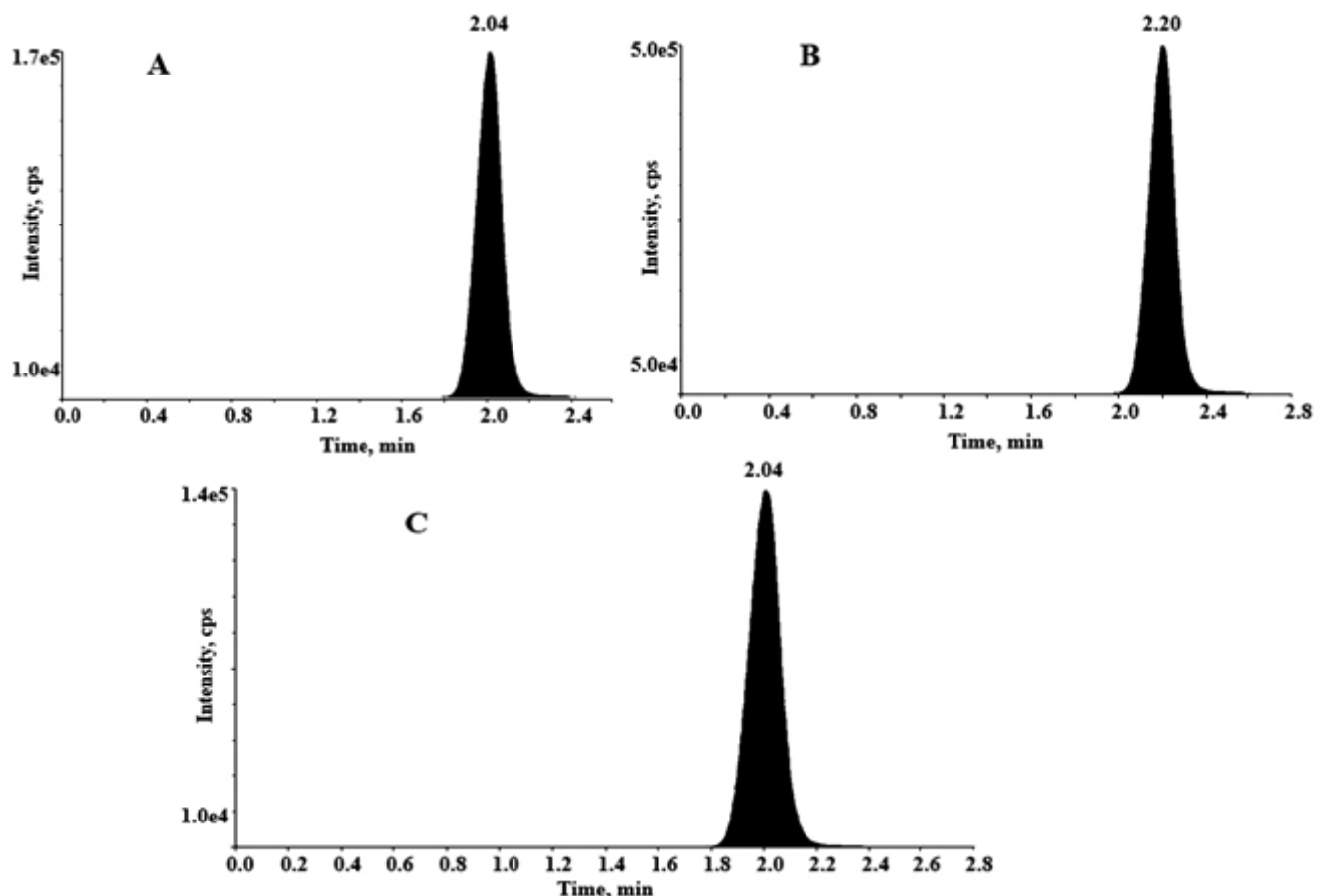

Figure 4: A representative standard chromatogram of (A) VEN (B) ODV (C) IS Cetrizine.

Six replicates of the blank matrix and lower limit of quantitation (LLOQ) spiked singly in each replicate using proposed extraction procedure was prepared. The interference at the retention time (RT) of VEN and ODV was checked by equating the response of the blank matrix compared to that of the mean response of the extracted sample at LLOQ level (Figure 5).

Similarly the meddling of the matrices at the RT of internal standard was evaluated by equating the response of the blank matrix to that of the mean response of the extracted internal standard. Selectivity was performed in six different lots of rat plasma was checked using two anticoagulants, namely, Adenine Citrate Dextrose Phosphate (ADCP) and EDTA. No significant interference was observed at the retention time of drug VEN (analyte), ODV (metabolite) and cetirizine (IS) in all the batches screened. \% RSD of the RT of both the analyte and the IS was less than $5 \%$. 

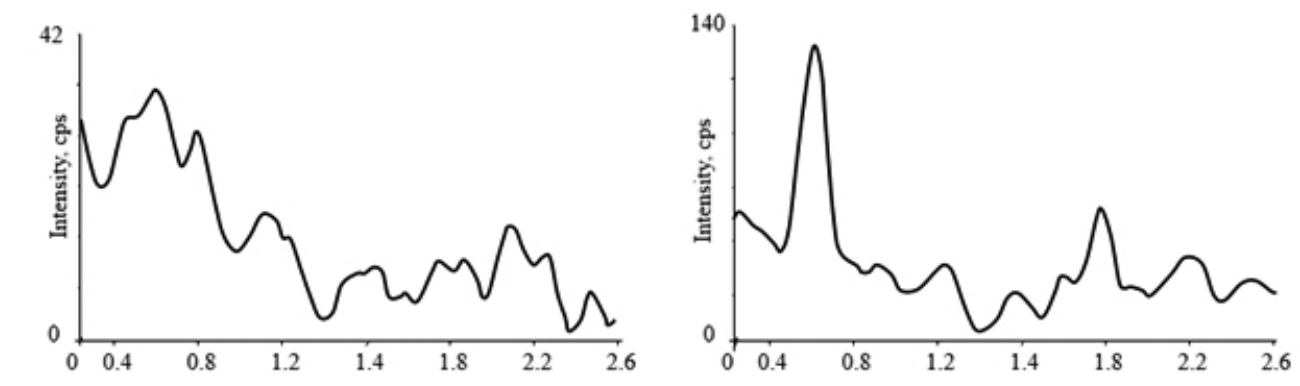

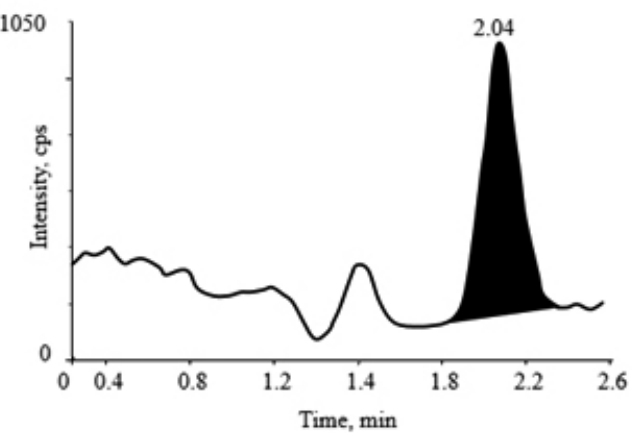

A

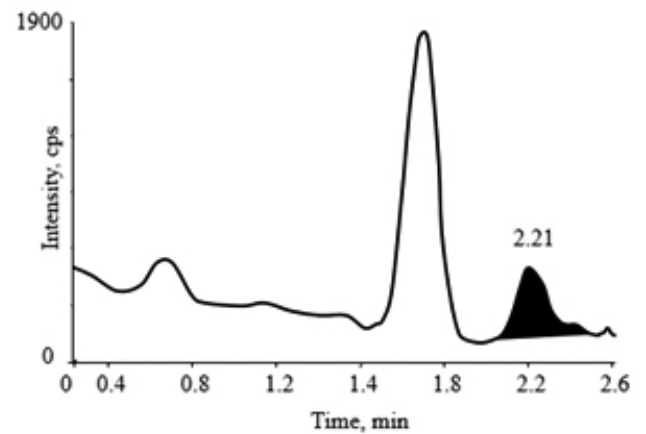

B

Figure 5. Chromatograms of blank and the sample at the RT of (A) VEN and (B) ODV.

\section{Linearity and calibration standard}

Linearity assessment was performed considering eight calibration points and back-calculating the concentrations of injected calibration curve standards. Regression equation having suitable weighting factor was applied for determining the concentration/detector response correlation. Regression equation with a weighting factor of $1 / \mathrm{X}^{2}$ of drug to IS concentration was judged to produce the best fit for the concentration-detector response relationship for drug VEN and drug ODV in rat plasma.

Eight point calibration peak area ratios of VEN and ODV to internal standard (cetirizine) was found to be linear over the range of $1.03 \mathrm{ng} / \mathrm{mL}$ to $453.50 \mathrm{ng} / \mathrm{mL}$ for drug VEN and $1.32 \mathrm{ng} / \mathrm{mL}$ to $585.21 \mathrm{ng} / \mathrm{mL}$ for its metabolite ODV. The calibration curve was achieved by a following equation using linear regression analysis of the spiked calibration standard using an $1 / \mathrm{x}^{2}$ as a weighting factor: $\mathrm{y}=\mathrm{mx}+\mathrm{c}$ Where, $\mathrm{y}=$ peak area ratio of drug to internal standard (IS), $\mathrm{m}=$ slope of calibration curve, $\mathrm{x}=$ concentration of drug, $\mathrm{c}=$ $\mathrm{y}$-axis intercept of the calibration curve for both analyte and minimum residual and a regression coefficient $>0.9980$.

Precision and Accuracy

For method validation QCs samples were prepared in three concentrations of low, medium and high concentration within the linear range. Six replicates of each QCs sample were analyzed together with a set of calibration standard. The accuracy of sample preparation was determined by injection of calibration samples and three levels of QCs samples in six replicates. The accuracy was expressed in $\%$ bias. The precision was expressed as the percent coefficient of variance $(\% \mathrm{CV})$ or relative standard deviation (RSD) of replicate measurement.

The precision of the assay was measured by the percent coefficient of variation over the concentration range of LLOQ QC, LQC, MQC and HQC samples respectively during the course of validation. The accuracy of the assay was defined as the absolute value of the ratio of the calculated mean values of the LLOQ, low, middle and high quality control samples to their respective nominal values, expressed in percentage.

For VEN

The accuracy and precision studies for VEN were performed at three concentration level of 2.80, 239.44, $341.42 \mathrm{ngmL}^{-1}$ and at LLOQ level of 1.03 ngmL ${ }^{-1}$. Intra batch precision ranged from $1.77 \%(\mathrm{HQC})$ to $6.39 \%(\mathrm{LQC})$ and between batch accuracy in terms of recovery ranged from $88.574 \%$ (MQC) to $106.996 \%$ (HQC). Inter batch precision ranged from $2.26 \%$ (HQC) to 10.96 $\%$ (LQC) and between batch accuracy ranged from $93.333 \%$ (LQC) to 104.693 $\%$ (HQC).
For $O D V$

The accuracy and precision studies for the metabolite ODV were performed at three concentration level of $3.58,305.84$ and $442.95 \mathrm{ngmL}^{-1}$ and at LLOQ level of $1.32 \mathrm{ngmL}^{-1}$. The Intraday precision ranged from 1.70 $\%$ (HQC) to $11.94 \%$ (LLOQ QC) and between batch accuracy ranged from $92.024 \%$ (HQC) to $103.818 \%$ (LQC), while inter-day precision ranged from $1.88 \%$ (HQC) to $9.91 \%$ (LLOQ QC) and between batch accuracy ranged from $90.739 \%$ (HQC) to $97.377 \%$ (LQC). The results are summarized in table 4 .

\section{$L O D$ and $L L O Q$}

The LOD for VEN and ODV were defined as the drug concentration in the plasma after sample preparation method that corresponds to three times the baseline noise ( $\mathrm{S} / \mathrm{N} \geq 3$ ). The LLOQ was defined as the concentration of sample that can be quantified with $<20 \%$ deviation $(\mathrm{S} / \mathrm{N} \geq 10)$.

The lowest limit of quantification (LLOQ) for VEN was found to be 1.03 $\mathrm{ng} / \mathrm{mL}$. The precision and accuracy for VEN (1.03 ng/mL-STD A) were found to be $7.83 \%$ and $116.02 \%$, respectively. The lowest limit of quantification (LLOQ) for ODV was obtained $1.32 \mathrm{ng} / \mathrm{mL}$, while the precision and accuracy for ODV $(1.32 \mathrm{ng} / \mathrm{mL}-\mathrm{STD}$ A) were found to be $5.90 \%$ and $94.70 \%$, respectively.

Recovery

To ascertain the recovery of the drug and its metabolite, a comparative study of the peak area of the two analytes from the samples spiked into blank prior to extraction and after the extraction. The recovery studies were performed at three concentration points of low, medium and high concentration range. Recovery for VEN was found to be $72.55 \%$ while it's Precision in terms of $\%$ $\mathrm{CV}$ was found to be $5.34 \%$. Recovery for ODV was found to be $73.81 \%$, and precision in terms of $\% \mathrm{CV}$ was 5.78 , the internal standard recovery was found Nominal $74.75 \%$, and Precision (\% CV) 3.04\%. The details of the recovery studies are mentioned in table 5.

Goodness of Fit

The goodness of fit analysis was performed by considering three sets of the data of the accuracy and precision batches and back calculating the concentrations of calibration curve standards meeting the acceptance criteria using $1 / x$ and $1 / x^{2}$ weighting. After performing the goodness of fit, $1 / x^{2}$ was found to be the best fit for regression. The results of the goodness of fit analysis are referred to in table 6 . 
J. Chil. Chem. Soc., 61, No 3 (2016)

Table 4. Precision \& Accuracy data for VEN ( $\mathrm{n}=6$ ) and ODV.

\begin{tabular}{|c|c|c|c|c|c|c|c|c|}
\hline \multirow[t]{2}{*}{ Sample } & \multirow[b]{2}{*}{ QCID } & \multirow{2}{*}{$\begin{array}{c}\text { Theoretical } \\
\text { content (ng } \\
\left.\mathrm{mL}^{-1}\right)\end{array}$} & \multicolumn{3}{|c|}{ Intra-Batch } & \multicolumn{3}{|c|}{ Inter-Batch } \\
\hline & & & $\begin{array}{c}\text { Mean Concentration } \\
\text { Observed (ng } \\
\left.\mathrm{mL}^{-1}\right)\end{array}$ & $\begin{array}{l}\text { Accuracy } \\
(\%)\end{array}$ & $\begin{array}{l}C V^{\mathrm{a}} \\
(\%)\end{array}$ & $\begin{array}{c}\text { Mean Concentration } \\
\text { Observed (ng } \\
\left.\mathrm{mL}^{-1}\right)\end{array}$ & $\begin{array}{l}\text { Accuracy } \\
(\%)\end{array}$ & $\begin{array}{l}\mathrm{CV}^{\mathrm{a}} \\
(\%)\end{array}$ \\
\hline \multirow{4}{*}{ VEN } & $\begin{array}{c}\text { LLOQ } \\
\text { QC }\end{array}$ & 1.03 & 1.042 & 101.133 & 6.39 & 1.078 & 104.693 & 10.58 \\
\hline & LQC & 2.80 & 2.578 & 92.083 & 3.23 & 2.613 & 93.333 & 10.96 \\
\hline & MQC & 239.44 & 212.082 & 88.574 & 4.63 & 234.643 & 97.997 & 6.80 \\
\hline & HQC & 341.42 & 365.307 & 106.996 & 1.77 & 321.198 & 94.077 & 2.26 \\
\hline \multirow{4}{*}{ ODV } & $\begin{array}{c}\text { LLOQ } \\
\text { QC }\end{array}$ & $1.32 \mathrm{ng} / \mathrm{mL}$ & 1.349 & 102.231 & 11.94 & 1.280 & 96.970 & 9.09 \\
\hline & LQC & $3.58 \mathrm{ng} / \mathrm{mL}$ & 3.717 & 103.818 & 5.75 & 3.486 & 97.377 & 9.91 \\
\hline & MQC & $305.84 \mathrm{ng} / \mathrm{mL}$ & 305.808 & 99.990 & 7.29 & 287.370 & 93.961 & 7.46 \\
\hline & HQC & $442.95 \mathrm{ng} / \mathrm{mL}$ & 407.622 & 92.024 & 1.70 & 401.929 & 90.739 & 1.88 \\
\hline
\end{tabular}

${ }^{\mathrm{a}}$ Coefficient of variance $($ percentage $)=$ standard deviation divided by concentration found $\mathrm{x} 100$

Table 5: Quality parameters of proposed LC-MS/MS method for recovery studies; VEN ( $n=6)$, ODV ( $n=6)$ and IS ( $n=6$ )

\begin{tabular}{|c|c|c|c|c|c|c|c|}
\hline \multirow{3}{*}{ Sample } & \multirow{3}{*}{ QC } & \multicolumn{2}{|c|}{ LQC } & \multicolumn{2}{|c|}{ MQC } & \multicolumn{2}{|c|}{ HQC } \\
\hline & & \multicolumn{2}{|c|}{ Peak Response } & \multicolumn{2}{|c|}{ Peak Response } & \multicolumn{2}{|c|}{ Peak Response } \\
\hline & & $\begin{array}{l}\text { Un-extracted } \\
\text { Sample }\end{array}$ & $\begin{array}{l}\text { Extracted } \\
\text { Sample }\end{array}$ & $\begin{array}{l}\text { Un-extracted } \\
\text { Sample }\end{array}$ & $\begin{array}{l}\text { Extracted } \\
\text { Sample }\end{array}$ & $\begin{array}{l}\text { Un-extracted } \\
\text { Sample }\end{array}$ & $\begin{array}{l}\text { Extracted } \\
\text { Sample }\end{array}$ \\
\hline \multirow{6}{*}{ VEN } & Mean & 107430.2 & 79292.2 & 6711528.5 & 4577348.8 & 9943201.0 & 7519800.7 \\
\hline & SD & 3355.97 & 1770.82 & 61287.29 & 34260.21 & 70258.57 & 46009.94 \\
\hline & CV (\%) & 3.12 & 2.23 & 0.91 & 0.75 & 0.71 & 0.61 \\
\hline & \% Recovery & \multicolumn{2}{|c|}{73.81} & \multicolumn{2}{|c|}{68.20} & \multicolumn{2}{|c|}{75.63} \\
\hline & Mean Recovery & \multicolumn{6}{|c|}{$72.55(\%)$} \\
\hline & CV of $\%$ Recovery & \multicolumn{6}{|c|}{$5.34(\%)$} \\
\hline \multirow{6}{*}{ ODV } & Mean & 78559.2 & 59393.3 & 4937609.0 & 3403775.5 & 6544035.2 & 5031392.0 \\
\hline & SD & 1017.18 & 781.77 & 41318.31 & 40538.90 & 55487.46 & 11170.27 \\
\hline & CV (\%) & 1.29 & 1.32 & 0.84 & 1.19 & 0.85 & 0.22 \\
\hline & \% Recovery & \multicolumn{2}{|c|}{75.60} & \multicolumn{2}{|c|}{68.94} & \multicolumn{2}{|c|}{76.89} \\
\hline & Mean Recovery & \multicolumn{6}{|c|}{$73.81 \%$} \\
\hline & CV of $\%$ Recovery & \multicolumn{6}{|c|}{$5.78 \%$} \\
\hline \multirow{6}{*}{ IS } & Mean & 1996443.8 & 1541738.8 & 2073258.0 & 1539737.3 & 2044544.0 & 1487566.3 \\
\hline & $\mathrm{SD}$ & 35535.59 & 23157.59 & 9928.66 & 13247.11 & 7827.31 & 20254.41 \\
\hline & CV (\%) & 1.78 & 1.50 & 0.48 & 0.86 & 0.38 & 1.36 \\
\hline & $\%$ Recovery & \multicolumn{2}{|c|}{77.22} & \multicolumn{2}{|c|}{74.27} & \multicolumn{2}{|c|}{72.76} \\
\hline & Mean Recovery & \multicolumn{6}{|c|}{$74.75 \%$} \\
\hline & CV of $\%$ Recovery & \multicolumn{6}{|c|}{$3.04 \%$} \\
\hline
\end{tabular}

Table 6. Goodness of Fit for VEN and ODV.

\begin{tabular}{|c|c|c|c|}
\hline \multirow{3}{*}{ Sample } & Summary:- & \multicolumn{2}{|c|}{ Sum of \% RE } \\
\cline { 2 - 4 } & PACC No:- & $1 / \mathrm{X}^{1}$ & $1 / \mathrm{X}^{2}$ \\
\hline \multirow{4}{*}{ VEN } & 01 & 110.78 & 83.07 \\
\cline { 2 - 4 } & 02 & 109.60 & 82.98 \\
\cline { 2 - 4 } & 03 & 75.67 & 70.50 \\
\cline { 2 - 4 } & Mean & 98.684 & 78.849 \\
\hline \multirow{4}{*}{ ODV } & 01 & 136.11 & 92.80 \\
\cline { 2 - 4 } & 02 & 136.14 & 86.83 \\
\cline { 2 - 4 } & 03 & 240.86 & 77.04 \\
\cline { 2 - 4 } & Mean & 171.039 & 85.555 \\
\hline
\end{tabular}


Ruggedness

One complete precision and accuracy batch was processed and analyzed by different analyst using different column and different sets of solutions. The mean accuracy for VEN ranged from $98.706 \%$ (LLOQ QC) to $110.548 \%$ (HQC) and the precision ranged from $2.30 \%$ (MQC) to $6.40 \%$ (LQC). The mean accuracy for drug ODV ranged from $95.653 \%$ (HQC) to $110.056 \%$ (LQC) and the precision ranged from $1.56 \%$ (MQC) to $7.00 \%$ (LQC). The ruggedness studies are summarized in table 7.

Table 7. Ruggedness Data for VEN and ODV using mean of 6 replicates at each concentration $(n=6)$.

\begin{tabular}{|c|c|c|c|c|c|}
\hline \multirow{2}{*}{ Sample } & QC ID & $\begin{array}{c}\text { Theoretical content } \\
\left(\mathrm{ng} \mathrm{mL}^{-1}\right)\end{array}$ & $\begin{array}{c}\text { Mean Concentration } \\
\text { Observed (ng mL }\end{array}$ & $\begin{array}{c}\text { Accuracy } \\
(\%)\end{array}$ & $\begin{array}{c}\mathrm{CV}^{\mathrm{a}} \\
(\%)\end{array}$ \\
\hline \multirow{4}{*}{ VEN } & LLOQ QC & 1.03 & 1.017 & 98.706 & 5.00 \\
\cline { 2 - 7 } & LQC & 2.80 & 2.770 & 98.929 & 6.40 \\
\cline { 2 - 7 } & MQC & 239.44 & 239.010 & 99.820 & 2.30 \\
\cline { 2 - 7 } & HQC & 341.42 & 377.432 & 110.548 & 3.44 \\
\hline \multirow{5}{*}{ ODV } & LLOQ QC & 1.32 & 1.310 & 99.242 & 5.04 \\
\cline { 2 - 7 } & LQC & 3.58 & 3.940 & 110.056 & 7.00 \\
\cline { 2 - 7 } & MQC & 305.84 & 309.873 & 101.319 & 1.56 \\
\cline { 2 - 7 } & HQC & 442.95 & 423.693 & 95.653 & 3.76 \\
\hline
\end{tabular}

Mean of 6 replicates at each concentration $(n=6) ; \mathrm{CV}(\%)$ : Coefficient of variance (percentage) $=$ standard deviation divided by concentration found $\mathrm{x} 100$

\section{CONCLUSIONS}

The LC-MS/MS bio-analytical method for simultaneous estimation of venlafaxin hydrochloride and its active metabolite O-desmethyl venlafaxine was develop and validated in rat plasma. The proposed method has significant advantages over those, previously reported in terms, selectivity, sensitivity, linearity, precision and accuracy, ruggedness presented and short run time. The method was validated over a concentration range of $1.03 \mathrm{ng} / \mathrm{mL}$ to $453.50 \mathrm{ng} /$ $\mathrm{mL}$ for venlafaxine and $1.32 \mathrm{ng} / \mathrm{mL}$ to $585.21 \mathrm{ng} / \mathrm{mL}$ for ODV. Significantly lower detection limit allows to carrying out the pharmacokinetic studies to obtain realistic pharmacokinetic parameter. The solid phase extraction procedure provided consistent and reproducible recoveries for drugs as well as its active metabolite with no interference at their retention time (RT). The result indicates that the method could be considered suitable for carry out simultaneous preclinical pharmacokinetics studies for venlafaxine and its active metabolite ODV in rat plasma and other biological samples.

\section{ACKNOWLEDGEMENTS}

The authors would like to extend their sincere appreciation to the Deanship of Scientific Research at King Saud University for funding this work through the Research group No. (RG-1437-031).

\section{REFERENCES}

1. I. M. Whyte, A. H. Dawson and N. A. Buckley, QJM-Int J Med. 96, 369, (2003).

2. E.A. Muth, J.T. Haskins, J. A. Moyer, G. E. Husbands, S. T. Nielsen and E. B. Sigg, Biochem. Pharmacol. 35, 4493, (1986).

3. F. P. Bymaster, L. J. Dreshfield-Ahmad, P. G. Threlkeld, J. L. Shaw, L. Thompson, D. L. Nelson, S. K. Hemrick-Luecke and D. T. Wong, Neuropsychopharmacology, 25, 871, (2001).

4. S. R. Howell, G. E. M. Husbands, J. A. Scatina and S. F. Sisenwine, Xenobiotica, 23, 349, (1993).

5. Mayo Clinic staff (2005). "Beyond hormone therapy: Other medicines may help". Hot flashes: Ease the discomfort of menopause. Mayo Clinic. Retrieved 20 january 2015.

6. C. E. Schober and N. T. Ansani, Ann Pharmacother. 37, 1703, (2003).

7. D. R. Grothe, B. Scheckner and D. Albano, Pharmacotherapy, 24, 621, (2004).

8. E. A. Muth, J. A. Moyer, T. Haskins, T. H. Andree and G. E. M. Husbands, Drug Dev. Res. 23,191, (1991).

9. S. Cherkaoui, S. Rudaz, E. Varesio and J.-L. Veuthey, Electrophoresis, 22, 491, (2001).

10. S. Cherkaoui, S. Rudaz, E. Varesio and J.-L. Veuthey, Electrophoresis, 22, 3308, (2001).
11. S. Rudaz, C. Stella, A. E. Balant-Gorgia, S. Fanali and J. L. Veuthey, J. Pharm. Biomed. Anal. 23, 107, (2000).

12. S. Rudaz, J. L. Veuthey, C. Desiderio and S. Fanali, Chromatographia, $50,369,(1999)$.

13. L. Labat, M. Deveaux, P. Dallet and J. P. Dubost. J. Chromatogr. B., $773,17,(2002)$.

14. G. R. Shah, B. T. Thaker, K. R. Surati and M. H. Parabia, Anal. Sci. 25, 1207, (2009).

15. J. Bhatt, A. Jangid, G. Venkatesh, G. Subbaiah and S. Singh. J. Chromaotr. B. $829,75,(2005)$

16. S. K. Dubey, R. N. Saha, H. Jangala and S. Pasha, J. Pharm. Anal. 3, 466, (2013).

17. K. F. Ilett, J. H. Kristensen, L. P. Hackett, M. Paech, R. Kohan and J. Rampono, Braz. J. Clin. Pharmacol. 53, 17, (2002).

18. M. A. Matoga, F. B. Pehourcq, K. B. Titier, F. B. Dumora, and C. A. Jarry, J. Chromatogr. B. 760, 213, (2001).

19. L. Dutta, S. I. Ahmad, S.K. Mukherjee, S. Mishra, A. Khuroo, and T. Monif, Biomed. Chromatogr. 27, 622, (2013).

20. D. C. Reddy, A. T. Bapuji, V.S. Rao, V. Himabindu and S. Ravinder, J. Liq. Chromatogr. \& Rel. Technol. 36, 897, (2013).

21. L. Kang, H. W. Jun, and J. W. McCall, J. Pharm. Biomed. Anal. 19, 737 , (1999).

22. X. Wang, J. A. Paul, T. N. Nanovskaya, G. D. V. Hankins and M. S. Ahmed, J. Pharm. Biomed. Anal. 98, 107, (2014). 